\title{
Influence of Heat Treatment on Microstructure and Hardness of Nickel Aluminium Bronze (Cu-10al-5ni-5fe)
}

\author{
Prabhash Jain ${ }^{1}$, Praveen Kumar Nigam ${ }^{2}$ \\ ${ }^{I}$ (Head, Department of Mechanical, BUIT, BU, Bhopal, India) \\ ${ }^{2 \#}$ (Department of Mechanical, BUIT, Bhopal, India)
}

\begin{abstract}
In this investigation two types of heat treatments, solutionizing and ageing were employed to nickelaluminium bronze (NAB alloy) containing $10 \% \mathrm{Al}, 5 \% \mathrm{Fe}$ and $5 \% \mathrm{Ni}$ as the alloying elements. Heat treatment was done to access their influence on the microstructural and hardness. Solutionizing temperature carried out at $850^{\circ} \mathrm{C}$ and $900^{\circ} \mathrm{C}$ for duration of $30 \mathrm{~min}, 60 \mathrm{~min}, 90 \mathrm{~min}$ and $120 \mathrm{~min}$. similarly, ageing was carried out at $300^{\circ} \mathrm{C}$ and $500^{\circ} \mathrm{C}$ for the duration of $120 \mathrm{~min}$ and $180 \mathrm{~min}$. The heat treated samples were subjected to water quenching in order to bring them to ambient temperature. Microstructural studies was also carried out of as cast alloy as well as after Solutionizing and Ageing.Hardness of the samples was measured in as cast and heat treated (solutionized and aged at different temperatures and durations) conditions. The hardness of the alloy increased after the solutionizing and ageing treatments compared to the as cast one. Also, the samples aged at $400^{\circ} \mathrm{C}$ for 3 hrs attained the highest hardness. Optimization was done based on the best combination of hardness and microstructural homogeneity attained by the samples during the heat treatment.
\end{abstract}

Keywords - NAB, Microstructure, Hardness, Solutionizing, Ageing

\section{INTRODUCTION}

Aluminium bronze is one of the versatile wear resisting engineering materials that work under a corrosive environment with high stress [1]. As we know that Aluminium bronze that is copper based alloy contains aluminium about 5 to $12 \%$ or sometimes up to $14 \%$ by weight with some optional alloying elements like $\mathrm{Fe}, \mathrm{Ni}, \mathrm{Mn}$ and $\mathrm{Si}$ etc. [2][3]. Nickel-aluminium bronze (NAB) belongs to group of aluminium bronzes. It contains 9-12 wt. \% aluminium with additions of iron and nickel up to $6 \mathrm{wt}$ \% [4].

Nickel-aluminum bronze is a series of copper-based alloy with additions of aluminum, nickel and iron. Combined with high strength, it shows good resistance to corrosion and wear, which makes it one of the most versatile engineering materials. It is widely used as engineering parts, such as various worm-gears, gears, bearings, dies, valves and propellers [5]. The Chemical Composition of nickel aluminum bronze are $78 \% \mathrm{Cu}$ min, $10.0 \%$ to $11.5 \% \mathrm{Al}, 3.0 \%$ to $5.0 \% \mathrm{Fe}, 3.5 \% \mathrm{Mn} \max , 3.0 \%$ to $5.5 \% \mathrm{Ni}, 0.5 \%$ max other (total)[6] .

The main microstructural phase of such copper alloys is the fcc $\mathrm{Cu}$ rich $\alpha$ phase. $\mathrm{Cu}-10 \mathrm{Al}$ binary alloys suffer from the formation of brittle eutectoid phases limiting their technical use. Alloying with $\mathrm{Ni}$ (about $5 \mathrm{wt} \%$ ) retards this eutectoid formation and further alloying with $\mathrm{Fe}(3-5 \mathrm{wt} \%)$ leads to the formation of fine dispersed $\mathrm{Fe}_{3} \mathrm{Al}$ and $\mathrm{NiAl}$ type precipitates (so called k-phases) that usually do not tend to segregate at grain boundaries. In principle, such multiphase aluminum bronzes are heat treatable. Quenching from elevated temperature produces an extremely hard and brittle martensitic structure ( $\beta$-phase) and subsequent tempering may be used to produce the desired combination of strength and ductility [7].

\section{METHODOLOGY}

The methodology adopted to carry out the present study essentially involved alloy preparation by melting and casting technique, its heat treatment (solutionizing and ageing) over a range of temperatures and durations, optimization of heat treatment parameters (temperature and duration), sample preparation from the alloy in as cast and heat treated conditions, characterization of microstructural features and mechanical properties. A schematic representation of the adopted methodology is shown below (Fig 2.1): 


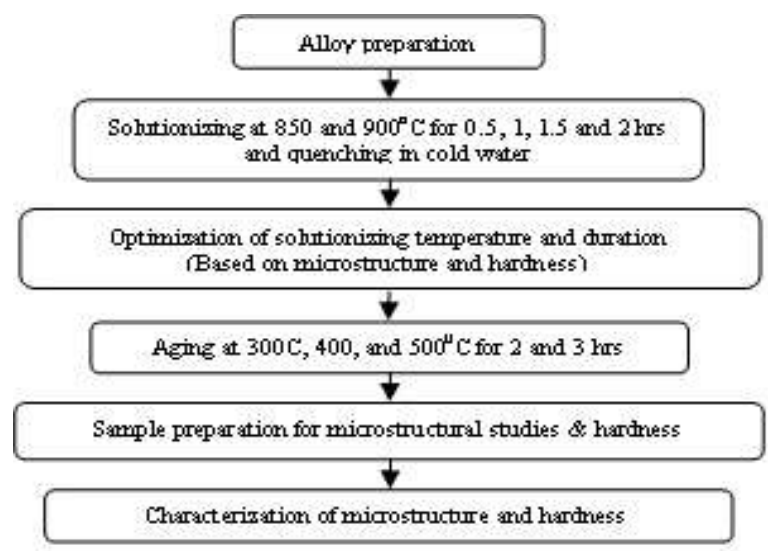

Fig: 2.1 - Flowchart of methodology adopted

\subsection{Alloy preparation}

\section{EXPERIMENTAL WORK}

The Al bronze with a nominal composition of $\mathrm{Cu}-10 \mathrm{Al}-5 \mathrm{Fe}-5 \mathrm{Ni}$ was synthesized using liquid metallurgy route. The process started with the preparation of the charge containing required quantities of different elements like $\mathrm{Cu}, \mathrm{Al}, \mathrm{Ni}$ and $\mathrm{Fe}$. Cu pieces were charged in a graphite crucible and melted employing an oil-fired furnace. The melt surface was covered with flux (Albral) and other alloying elements were added to the melt (maintained at $1170^{\circ} \mathrm{C}$ ) gradually. Care was taken to add the lower melting elements like $\mathrm{Al}$ to add at latter stages of melting with a view to reduce losses through vaporization. The melt was stirred manually for some time to facilitate dissolution of the alloying elements. After cleaning the melt surface, pouring was carried out in permanent moulds in the form of $14 \mathrm{~mm}$ diameter, $150 \mathrm{~mm}$ long cylindrical rods (Fig 3.5). In order to hold the solidification structure differences of die casting specimens at the minimum, the die molds have been used after being subjected to preheating at $450-500^{\circ} \mathrm{C}$.

\subsection{Heat treatment}

The heat treatment cycle employed in this investigation consisted of solutionizing and artificial ageing done in an electric heat treatment furnace (Fig 3.6).

\subsubsection{Solutionizing}

In order to further improve the mechanical properties of cast alloy (NAB) can be heat treated. The alloy was investigated in both as cast and heat-treated conditions. The solutionizing was done at different combinations of temperatures and times. Solutionizing was carried at 850 and $900^{\circ} \mathrm{C}$, for $0.5,1,1.5$ and $2 \mathrm{hrs}$, respectively. Water quenching was employed to bring the heat treated samples to ambient temperature after the solutionizing. There are eight specimens (A-H) taken for solutionizing as summarized below in Table 3.1

Table 3.1: Solutionizing time $\&$ temperature of as -cast nickel-aluminum bronze

\begin{tabular}{|c|c|c|c|c|c|c|c|c|}
\hline Sample no. $\rightarrow$ & A & B & C & D & E & F & G & H \\
\hline Temperature & $850{ }^{\circ} \mathrm{C}$ & $850{ }^{\circ} \mathrm{C}$ & $850{ }^{\circ} \mathrm{C}$ & $850{ }^{\circ} \mathrm{C}$ & $900{ }^{\circ} \mathrm{C}$ & $900{ }^{\circ} \mathrm{C}$ & $900{ }^{\circ} \mathrm{C}$ & $900{ }^{\circ} \mathrm{C}$ \\
\hline Time & $0.5 \mathrm{hr}$ & $1 \mathrm{hr}$ & $1.5 \mathrm{hr}$ & $2.0 \mathrm{hrs}$ & $0.5 \mathrm{hr}$ & $1 \mathrm{hr}$ & $1.5 \mathrm{hr}$ & $2.0 \mathrm{hrs}$ \\
\hline Quenching medium & Water & Water & Water & Water & Water & Water & Water & Water \\
\hline
\end{tabular}

\subsubsection{Aging}

In order to determine the role of the aging, the samples subjected to ageing that were prior solutionized at $900^{\circ} \mathrm{C}$ for $1.5 \mathrm{hrs}$. the specimens were aged at three temperature e.g. 300,400 and $500^{\circ} \mathrm{C}$ for 2 and $3 \mathrm{hrs}$, respectively. Water quenching was employed to bring the heat treated samples to ambient temperature after the solutionizing. There are six specimens (AA-AF) taken for ageing as summarized below in Table 3.2

Table 3.2: Ageing time \& temperature of solutionized nickel-aluminum bronze

\begin{tabular}{|c|c|c|c|c|c|c|}
\hline Sample no. $\rightarrow$ & AA & AB & AC & AD & AE & AF \\
\hline Temperature & $300{ }^{\circ} \mathrm{C}$ & $300{ }^{\circ} \mathrm{C}$ & $400{ }^{\circ} \mathrm{C}$ & $400{ }^{\circ} \mathrm{C}$ & $500{ }^{\circ} \mathrm{C}$ & $500{ }^{\circ} \mathrm{C}$ \\
\hline Time & 2 hrs. & $3 \mathrm{hrs}$. & $2 \mathrm{hrs}$. & $3 \mathrm{hrs}$. & $2 \mathrm{hrs}$. & $3 \mathrm{hrs}$. \\
\hline Quenching medium & Water & Water & Water & Water & Water & Water \\
\hline
\end{tabular}




\subsection{Microstructural examination}

Microstructural examination was carried out on metallographically polished samples using a Leica make computerized optical microscope attached with a digital photographic and data storage and retrieval system (Fig 3.1). The microstructure was studied of as-cast, solutionized and aged sample of NAB. The microstructure was studied in both states before and after heat treatment.

Cylindrical Specimens (20 mm diameter, $10 \mathrm{~mm}$ height) for microstructural examination were taken from the die mold casted specimens (Fig 3.2). The methodology adopted for sample preparation for this purpose involved polishing of samples using different grades of emery papers such as 60, 120, 240, 320,600, 800, 1000 $\& 1200$ grits, 1/0, 2/0,3/0, 4/0 grades in descending order. Care was taken to continue polishing on a specific grade of emery paper until the scratches/polishing marks created by the previous paper were totally removed. Also, the direction of polishing on a typical polishing paper was kept normal to that of the previous one. Polishing on emery papers was followed by cloth polishing using alumina suspension ( 0.5 to 1.0 micron) as an abrasive and liquid soap as a lubricant. In this case, the device used was a polisher equipped with a rotating wheel. The wheel was covered with a polishing cloth and it rotated at a controlled speed with the help of an electric motor and regulator assembly (Fig 3.3 \& 3.4). The samples were rinsed well with water and acetone in order to clean the specimen surface. The samples were then etched using potassium dichromate solution.

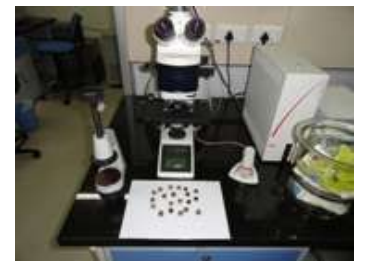

Fig: 3.1- Leica make computerized optical microscope

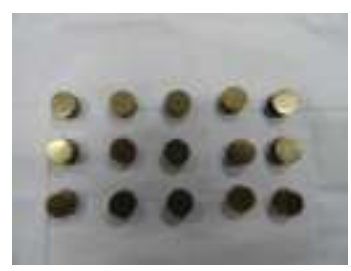

Fig: 3.2 - Different as-cast, Fig: 3.3 - Coarse solutionized \& aged sample polisher equipped with for Microstructural examination

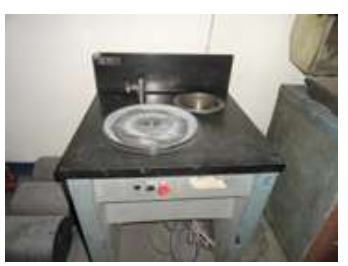

polisher equipped with fine emery paper

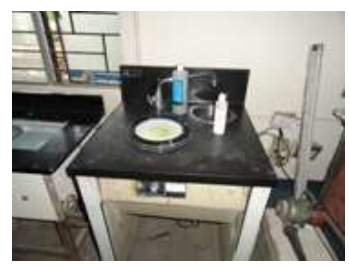

Fig: 3.4 - Fine polisher equipped with a rotating wheel covered with polishing cloth

\subsection{Hardness measurement}

\subsubsection{Preparation of test specimen}

Specimens (20 mm diameter, $10 \mathrm{~mm}$ thick) for hardness measurement were taken from the as cast sample. For hardness test the same specimen is used which was prepared for microstructural examination. The samples were polished metallographically prior to their hardness measurement (Fig: 3.7)

\subsubsection{Test procedure}

Hardness of the samples was measured using a Vickers hardness tester (Fig: 3.8) at an applied load of $31 \mathrm{~kg}$ for $60 \mathrm{sec}$. An average of 5 observations has been considered in this study.

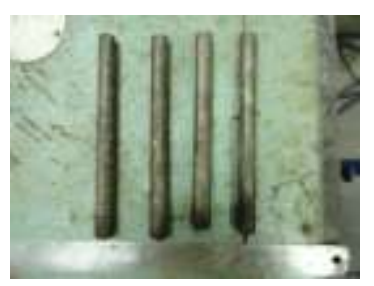

Fig: 3.5 - As-cast bar of NAB alloy

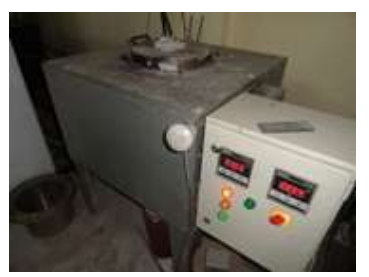

Fig: 3.6 - Electric heat treatment furnace

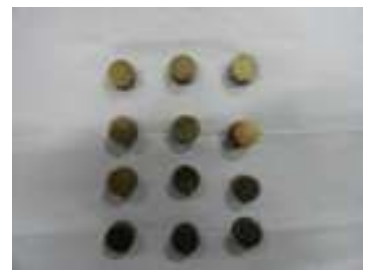

Fig: 3.7 - Specimen for Hardness measurement

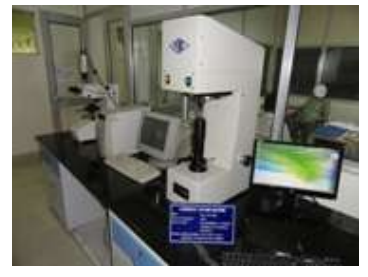

Fig: 3.8 - Vicker's

Hardness testing machine

\section{RESULTS}

\subsection{Microstructure}

Fig. 4.1 shows microstructural characteristics of the as cast NAB. The mode of distribution of different phases in the material system is shown in Fig. 4.1a. Needle like martensite and dark round particles may be seen in Fig. 4.1b. Other microconstituents like primary $\alpha$ surrounded by eutectoid $\left(\alpha+\mathrm{Ni}_{3} \mathrm{Al}\right)$ along with $\mathrm{Fe}$-rich phase are shown in Fig. 4.1c (regions marked by A, B and arrow respectively). The microstructure of the samples solutionized at 850 and $900^{\circ} \mathrm{C}$ are shown in Fig. 4.2 and 4.3 respectively. Effects of the solutionizing duration are also shown in the figures. Solutionizing at $850^{\circ} \mathrm{C}$ for $0.5 \mathrm{hr}$ led to the breaking of the as cast structure and dissolution of the eutectoid in the matrix and partial morphological modifications in grain boundary precipitates 
(Fig. 4.2a). A magnified view shows fine dispersion of the various microconstituents like limited quantity of the eutectoid and primary $\alpha$ along with feathery bainite and fine needles of martensite (Fig. 4.2b). Increasing the duration of solutionizing to $2 \mathrm{hrs}$ at the said temperature brought about a greater extent of dissolution/disappearance of the as cast structure and microstructural homogenization (Fig. 4.2c\&d versus). Solutionizing at $900^{\circ} \mathrm{C}$ led to a still greater extents of microstructural homogenization along with coarsening of (Fig. 4.3) compared to that at $850^{\circ} \mathrm{C}$ (Fig. 4.2). As far as the effect of solutionizing duration at $900^{\circ} \mathrm{C}$ is concerned, increasing the duration from 0.5 to $2 \mathrm{hrs}$ caused almost complete dissolution of the as cast structure, more effective microstructural homogenization and generation of very fine grains (Fig. 4.3a versus 4.3c). Microstructures of the aged alloy are shown in Fig. 4.4. Ageing at $300^{\circ} \mathrm{C}$ for $0.5 \mathrm{hrs}$ caused the re-precipitation of the $\gamma_{2}$ phase in a uniform manner along with some (undissolved) grain boundary precipitates (Fig. 4.4a\&b) while increasing ageing temperature and duration enhanced the process of dissolution of phases forming the eutectoid $\alpha+\gamma_{2}$ phase and making the structure more homogeneous and refined (Fig. 4.4c versus 4.4 a).

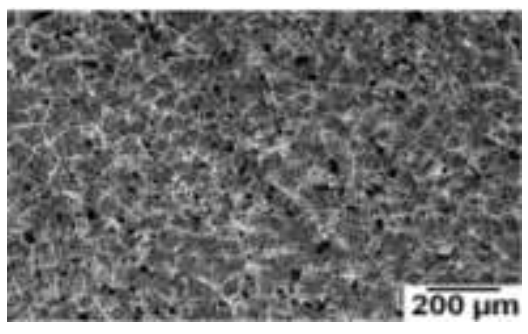

(a)

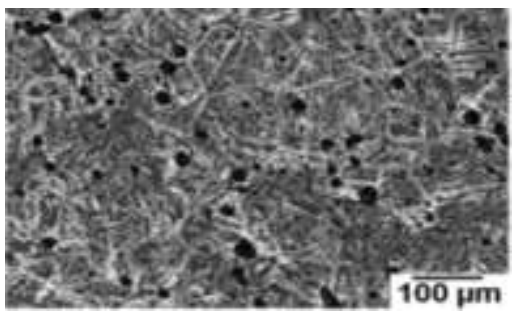

(b)

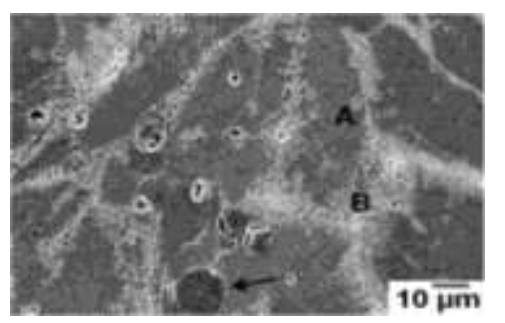

(c)

Fig: 4.1- Microstructural features of the as cast Ni-Al bronze (NAB) samples showing dendritic structure and different microconstituents [A: primary $\alpha, \mathrm{B}$ : eutectoid $\alpha+\gamma_{2}$ and arrow: Fe containing phases]

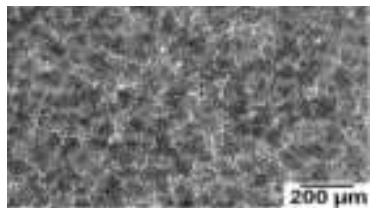

(a)

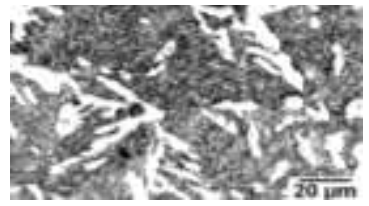

(b)

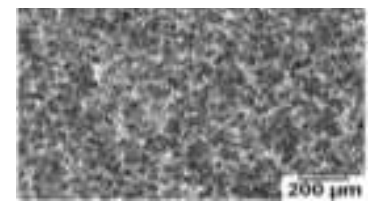

(c)

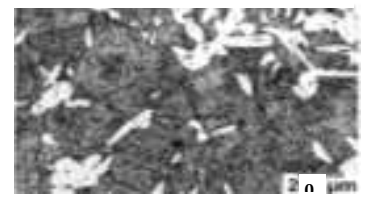

(d)

Fig: 4.2- Microstructural features of the Ni-Al bronze (NAB) samples solution treated at $850^{\circ} \mathrm{C}$ for (a\&b) 0.5 and (c\&d) $2 \mathrm{hrs}$ showing the elimination of as cast structure, improved degree of microstructural homogeneity and different microconstituents

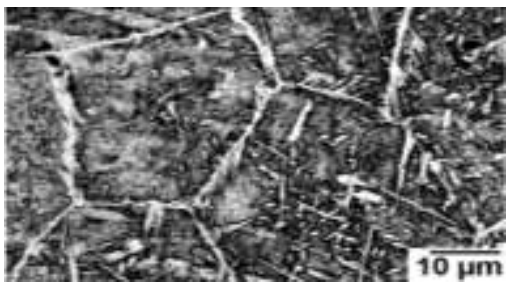

(a)

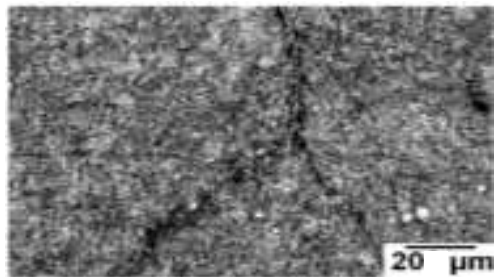

(b)

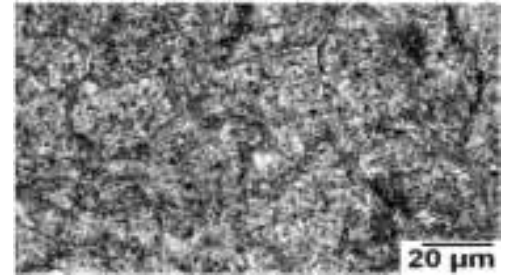

(c)

Fig: 4.3- Microstructural features of the Ni-Al bronze (NAB) samples solution treated at 900oC for (a) 0.5 , (b) 1.5 and (c) 2 hrs showing the elimination of the as cast structure, improved degree of microstructural homogeneity and different microconstituents]

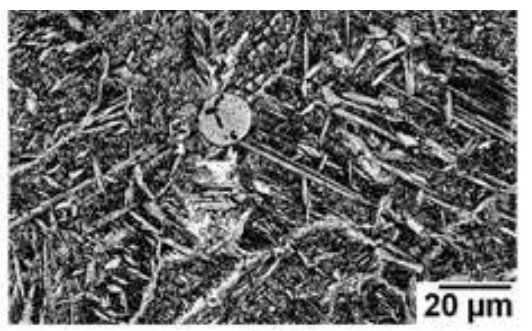

(a)

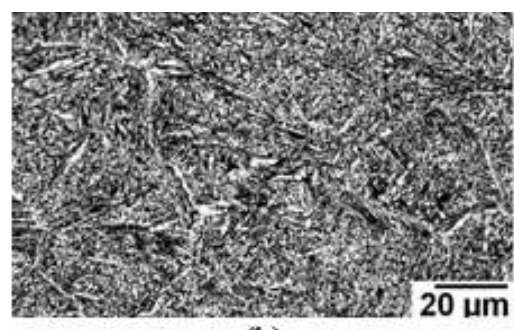

(b)

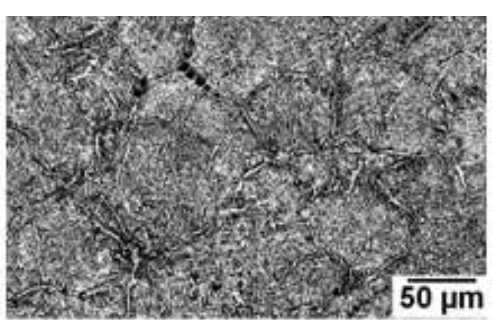

(c)

Fig: 4.4-Microstructural features of the Ni-Al bronze (NAB) samples solution treated at $850^{\circ} \mathrm{C}$ for $2 \mathrm{hrs}$ followed by ageing at (a) 300 and (b) $500^{\circ} \mathrm{C}$ for $2 \mathrm{hrs}$ and (c) $3 \mathrm{hrs}$ showing the elimination of the as cast structure, improved degree of microstructural homogeneity and different microconstituents 


\subsection{Hardness}

The hardness of the samples is plotted as a function of the duration of the (heat treatment) in Fig 4.5. The influence of treatment (solutionizing and ageing) temperature on the property may also be seen the figure. The data point on the hardness axis corresponding to zero duration represents the property of the as cast sample in the case of solutionized $\left(850\right.$ and $\left.900^{\circ} \mathrm{C}\right)$ samples whereas the one corresponding to the aged $(300,400$ and $500^{\circ} \mathrm{C}$ ) samples represents the hardness of the alloy solutionized at $900^{\circ} \mathrm{C}$ for $1.5 \mathrm{hrs}$. The hardness of the (as cast) samples increased after the ageing and solutionizing treatments. Also, the solutionized samples attained higher and higher hardness with increasing duration of the treatment initially irrespective of temperature. This was followed by the attainment of the hardness peak and softening of the alloy ultimately at still longer durations of solutionizing. An identical trend was observed as far as the influence of duration is concerned while a hardness increase was recorded with increasing solutionizing temperature. Ageing duration produced a mixed trend on hardness when compared with that of the prior solutionized one. For example, ageing caused a reduction in hardness over the prior solutionized samples while the trend reversed when the ageing was carried out at $300^{\circ} \mathrm{C}$ for $3 \mathrm{hrs}$. Moreover, increasing ageing duration led to higher hardness irrespective of temperature. On the contrary, increasing temperature led to an improvement in hardness initially followed a reversal in the trend at still higher temperatures. Trend of hardness in as-cast, solutionizing \& ageing is shown in Fig 4.6
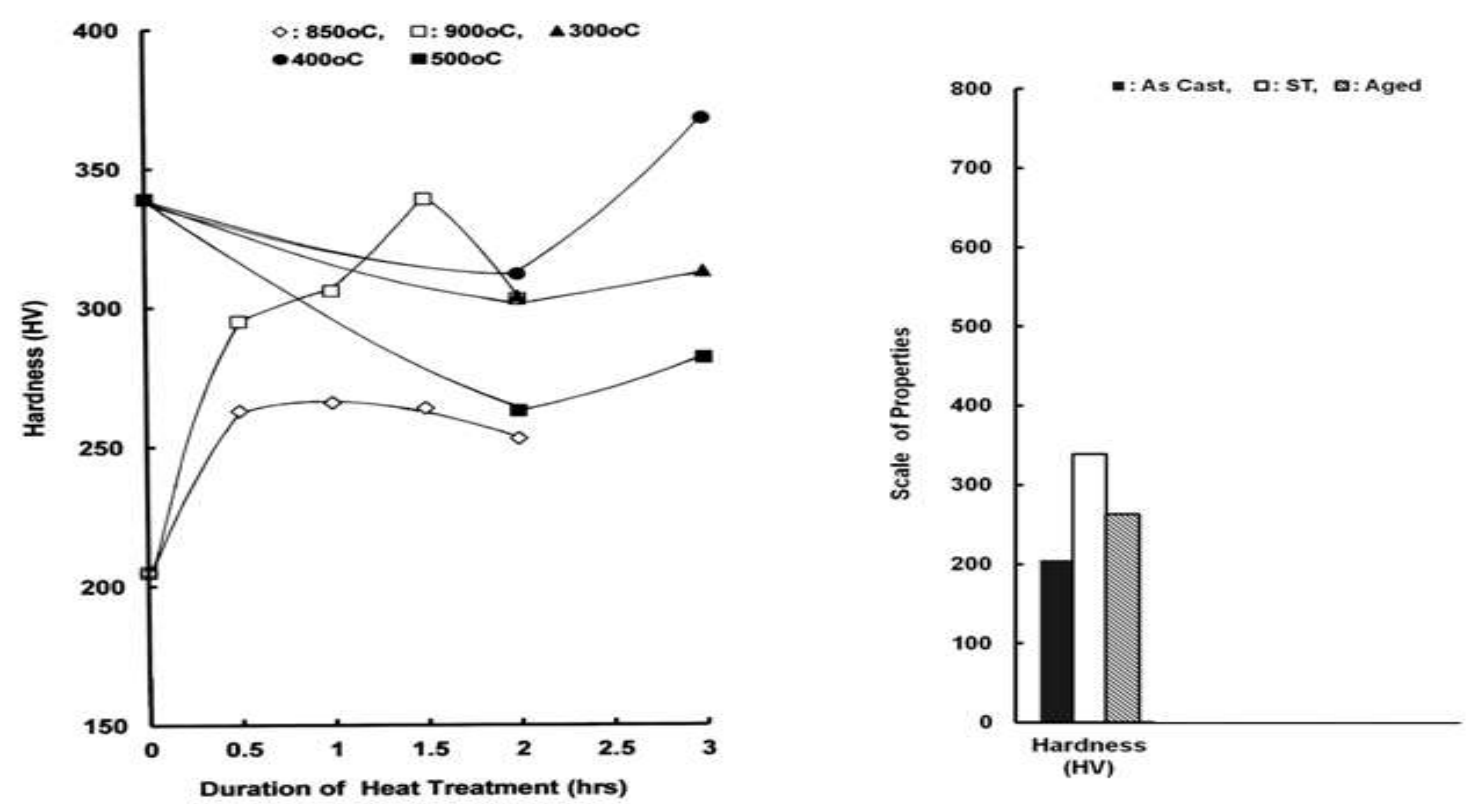

Fig: 4.5(Left) - Hardness of the bronze samples plotted as a function of the duration of solutionizing and ageing treatments. The effect of the temperature of solutionizing $\left(850\right.$ and $\left.900^{\circ} \mathrm{C}\right)$ and that of ageing $\left(300,400\right.$ and $\left.500^{\circ} \mathrm{C}\right)$ on the hardness property is also shown in the figure.

Fig: 4.6(Right) - Typical mechanical (hardness) property of the bronze samples in as cast and heat treated conditions [ST: solutionizing at $900^{\circ} \mathrm{C}$ for $1.5 \mathrm{hrs}$, Aged: ageing at $500^{\circ} \mathrm{C}$ for $2 \mathrm{hrs}$ ]

\section{Conclusion}

This chapter presents conclusions arrived at based on the results obtained and observations made in this investigation. The conclusions relate to the microstructural alterations brought about by heat treatment involving solutionizing and ageing and corresponding changes in mechanical properties such as hardness. Following are the conclusions drawn:

1. The alloy displayed primary $\alpha$, eutectoid $\alpha+\gamma_{2}$ as well as retained $\beta$ and martensite $\beta$ '. Heat treatment led to microstructural alterations significantly depending on the type and parameters employed. For example, solutionizing brought about microstructural homogenization through the disappearance of the as cast structure. The degree of (microstructural) homogeneity increased with the increasing duration and temperature of solutionizing. Coarsening of phases was also observed especially at higher temperatures and durations of the treatment. Ageing caused the formation of the eutectoid phase along with the retained/untransformed martensite and microconstituents displayed were $\alpha$. Ageing at $500^{\circ} \mathrm{C}$ led to the transformation of martensite into the stable eutectoid structure with better defined lamellae while the lamellae were not so well defined at $300^{\circ} \mathrm{C}$. Rising ageing duration led to structural coarsening. Formation of various microconstituents was also confirmed through X-ray diffraction studies. 
2. Hardness of the samples improved after heat treatment compared to the one in as cast condition. During solutionizing at $900^{\circ} \mathrm{C}$, the hardness decreased initially followed by the attainment of the minimum and a reversal in the trend at still longer durations ultimately tending to decrease once towards the end. A similar trend was also observed at $850^{\circ} \mathrm{C}$, except that no deterioration in hardness was observed towards the end of the treatment. Solutionizing temperature showed a mixed influence on hardness. Aged samples attained the highest hardness amongst all. Also, the hardness either remained practically unaffected or tended to decrease with increasing ageing duration while increasing ageing temperature up to $400^{\circ} \mathrm{C}$ led to a decreased in hardness while a further rise in temperature to $500^{\circ} \mathrm{C}$ delineated hardness to lie in between 300 and $400^{\circ} \mathrm{C}$.

3. The study suggests the microstructural features and hardness property of the samples to be affected by heat treatment significantly. The type (solutionizing and ageing) and parameters (temperature and duration) of heat treatment also affected the characteristics of the sample to a considerable extent. Accordingly, it emerges from the study that it is possible to obtain desired combinations of properties through optimizing the heat treatment type and parameters.

\section{REFERENCES}

[1] Mustafa Yas_ar, Yahya Altunpak, The effect of aging heat treatment on the sliding wear behaviour of $\mathrm{Cu}-\mathrm{Al}-\mathrm{Fe}$ alloys, Materials and Design 30 (2009) 878-884

[2] Yuanyuan Li, Tungwai Leo Ngai 1, Wei Xia, Mechanical, friction and wear behaviors of a novel high-strength, wear-resisting aluminum bronze, Wear 197 (1996) 130-136

[3] D.V. Kudashov, R. Zauter, H.R. Muller, Spray-formed high-aluminium bronzes, Materials Science and Engineering A 477 (2008) 43-49

[4] J.A. Wharton, R.C. Barik, G. Kear, R.J.K. Wood, K.R. Stokes, F.C. Walsh, The corrosion of nickel-aluminium bronze in seawater, Corrosion Science 47 (2005) 3336-3367

[5] CHEN Rui-ping, LIANG Ze-qin, ZHANG Wei-wen, ZHANG Da-tong, LUO Zong-qiang, LI Yuan-yuan, Effect of heat treatment on microstructure and properties of hot-extruded nickel-aluminum bronze, Trans. Nonferrous Met. SOC. China 17(2007) 12541258

[6] Harry Chandler, Heat Treater's Guide, Practices and Procedures for Nonferrous Alloys, 1996 By ASM International

[7] Thorsten Michler, Jorg Naumann, Influence of high pressure hydrogen on the tensile and fatigue properties of a high strength CuAl-Ni-Fe alloy, international journal of hydrogen energy 35(2010)11373-11377 